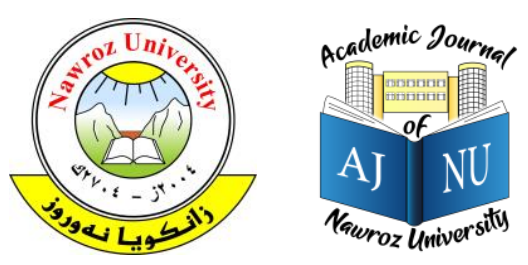

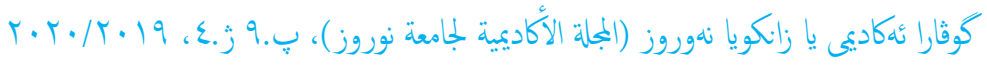

حقوق الطبع والنشر (2017. هذه مقالة الوصول اليها مفتوح موزعة تحت رخصة

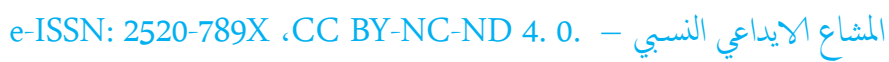

https://doi.org/10.25007/ajnu.v9n4a972

\title{
امكانية تبني العلاقة مع الزبون في المنظمات الخدمية
}

دراسة استطلاعية لآراء عينة من مديري المصارف الاهلية في مدينة دهوك

\author{
نزار عيى صديق، كلية الادارة والاقتصاد، جامعة دهوك، إقليم كوردستان العراق \\ شفان عبدالرمن جميل، كلية الادارة والاقتصاد، جامعة دهوك، إقليم كوردستان العراق
}

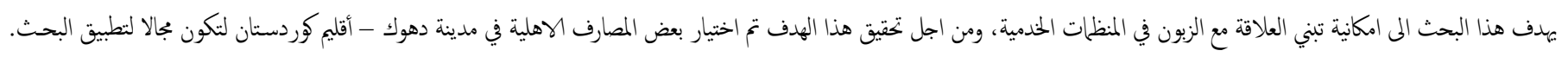

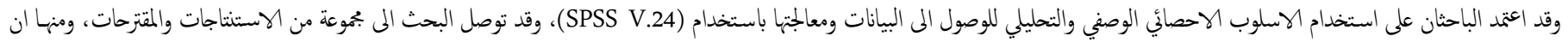

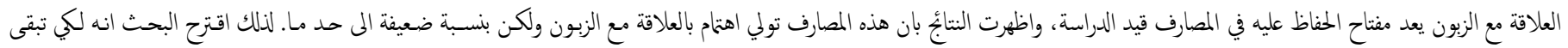

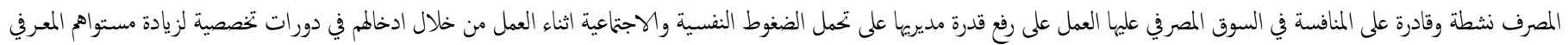

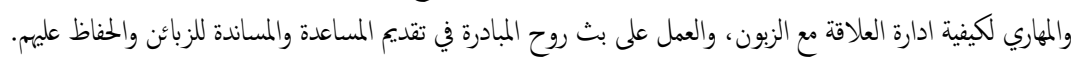
الكلمات الدالة: العلاقة مع الزبون - ابعاد العلاقة مع الزبون - المنظات الخدمية - دهوك / أقليم كوردستان

1. الحور الاول: منهجية البحث

ينعكس على كافة الأنشطة المصرفية بلا استثناء، ولكونها استراتيجية تهدف إلى فهم

1.1

حاجات ورغبات الزبائن الحاليين والمتوقعين، وإدارة هذه الحاجات والرغبات بأفضل الطرق وبالشكل المطلوب مع الإسراع في تحقيقها.

2.1 مشكلة البحث

من المهام الرئيسية لادارة العلاقة مع الزبون في اية منظمة هي تشكيل قاعدة بيانات خاصة بزبائها بشكل منطقي والتي من خلالها يتم تحديد أفضل الزبائن عنده ومعرفة احتياجاتهم وكذلك تحويل الزبائن المتملين المى زبائن موالين تربطهم بالمنظمة علاقة وثيقة وقوية (الحكيم وزوين، 2009: 2). ولكن تطبيق هذا المفهوم من الناحية التطبيقية قد يخلق المشاكل للمنظمة مثل تبادل المعرفة بين الزبون والمنظمة وتحديد الخيارات المقدمة للزبون وتحديد الخصائص الملموسة للخدمات والسلع وغيرها من المشكلات الاخرى التي يككن ان تعيق تطبيق وتنفيذ الاستراتيجيات الخاصة بادارة العلاقة مع الزبون في الواقع في المنظلات. وتكمن مشكلة البحث من خلال التساؤل

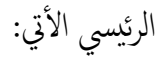

يعتبر الزبون بالنسبة للمنظات بشكل عام والخدمية منها بشكل خاص مركز اهتمام كبير نظرا لدوره الرئيسي في بقاهها في ظل التحولات الذي يشهدها عالم الأعمال اليوم من منافسة شديدة، ولكي تتميز المنظمة عن غيرها عليها أن تعرف زبائنها وان تتعرف على حاجتهم ورغباتهم لأهم الحجر الأساس الذي تبنى عليه الأعمال، وعلى المنظمة أن تمتلك إدارة قادرة على بقائها في الصف الأول والمحافظة على مكاتها بين المنظلات

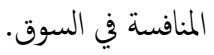
ومن أهم الإفرازات الإدارية الحديثة والتي تهدف إلى توفير حلول متكمالة لكافة المنظات ومنها المصارف، وتسمح لمم باتخاذ قرارات تسويقية من حيث التوقيت والنوعية، وتساعدهم على مواجهة التحديات، والمحافظة على مستوى ربحية الأعمال ومكانتها في السوق المصرفي، هو ما يعرف باستراتيجية "إدارة العلاقة مع الزبون" والتي يشار إلها بصطلح CRM وتأتي إدارة العلاقة مع الزبون كأفضل الحلول الممكنة والتي يكن استخداهما لموابحة الضغوطات والتحديات المستقبلية التي قد تواجه المصارف في اقليم كوردستان وخاصة الههلية منها، لما لها من مردود إيجاني 


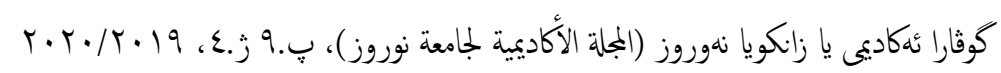

الدراسة دورا حما في ادارة العلاقة مع زبائها بأعتبارها تقنية او استراتيجية تسويقية معاصرة في اداء اعالها المصرفية).

\section{1 اساليب جمع البيانات}

بغية الحصول على البيانات اللازمة للوصول الى اهداف الدراسة واختبار فرضيتها تم الاعتاد في المجال النظري ما كتب في هذا الموضوع في الدوريات والرسائل والاطاريح والكتب وما نشر عنه في الشبكة العنكبوتية العالمية، اما في الاطار الميداني تم الاعتماد على استمارة الاستبانة والتي تعد اداة رئسية في جمع البيانات. وقد صممت استارة استبانة مؤلفة من المحورين، الاول تضمن الييانات التعريفية والتي تتعلق بالافراد المجيبين. والثاني تضمن ابعاد ادارة العلاقة مع الزبون. لغرض التاكد من قدرة استارة الاستبانة على قياس ابعاد متغير الدراسة، فقد اختبر الصدق الظاهري لققرات الاستبانة بعد اعدادها وعرضها على بمموعة من الخبراء والمختصين في العلوم الادارية للتاكد من صحة الفترات ومدى ملائمها لفرضية واهداف الدراسة. 7.1 قياس الصدق والثبات

اعتمد الباحثان بقياس صدق وثبات استمارة استبانة بواسطة اسلوب (3) موا موضح في الجدولين (1 و 2). ويوضح الجدول (Cronbach’s Alpha) ابعاد متغير الدراسة الواردة في الاستبانة. الجدول 1

Reliability Statistics

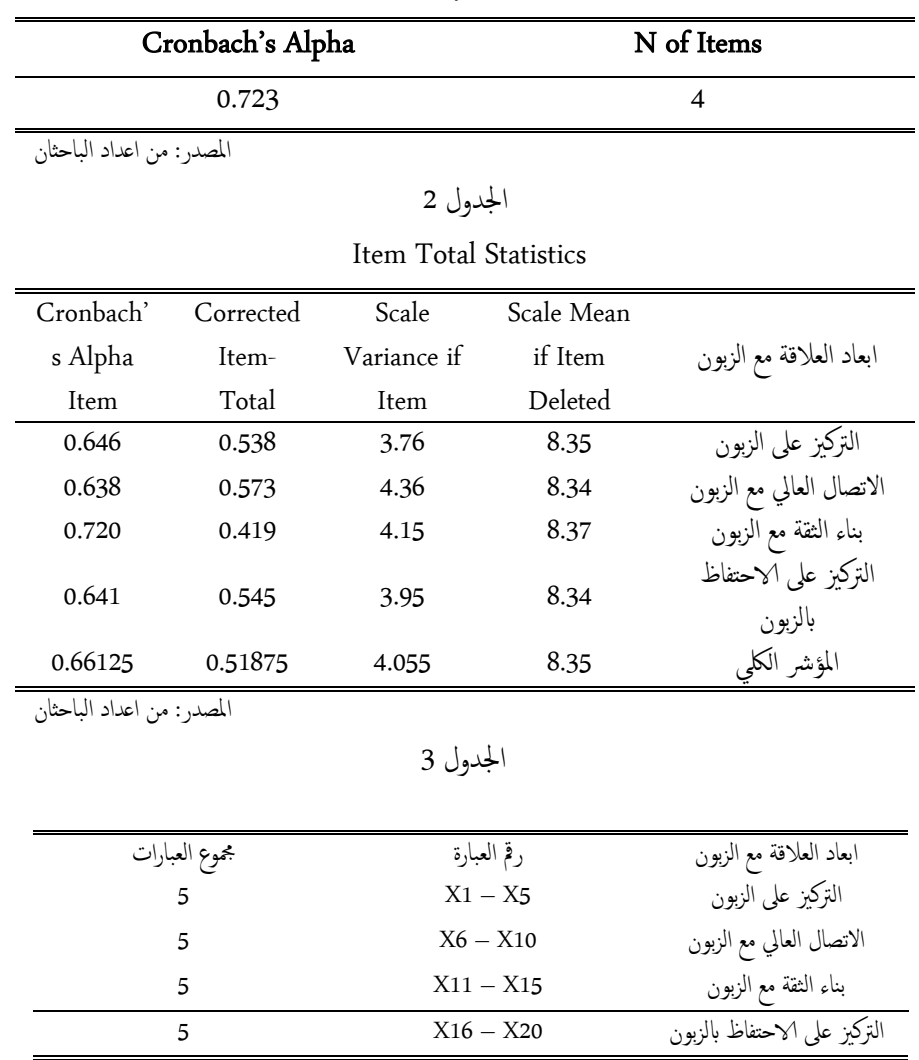

"هل ان المصارف الاهلية في مدينة دهوك تدرك دورها في مجال ادارة العلاقة مع زباينها" وينطلق من السؤال الرئيسي عدد من الاسئة الفرعية ومنها: - - هل هناك تصور واضح لدى مديري المصارف قيد الدراسة عن ادارة العلاقة مع

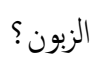
- - هل هذه الادارات تدرك ان نجاحما يتوقف على ابعاد ادارة العلاقة مع

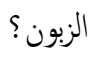
- - أي من أبعاد العلاقة مع الزبون تمثل الأولوية في المصارف قيد الدراسة؟ 3.1 ثكمن اهمية البحث في كون ادارة العلاقة مع الزبون مكونا اساسيا من مكونات التسويق بالعلاقة حيث انه يعد موضوعا اكلاديما هما جدا على مستوى الاطار النظري للدراسات التسويقية والبحث فيه يضيف شيئا محا للبحث والمعرفة العلمية فضلا عن كونه يعد مرجعا تسويقيا هما في المكتبات وللباحثين في هذا المجال. وتكمن الاهمية الميدانية بما ستفرز عنه الدراسة الميدانية من استنتاجات ومقترحات يككن للمصارف قيد الدراسة الاستفادة منها والعمل بها حاليا او مستقبلا من اجل ادارة العلاقة مع زبائها والحفاظ على سمتها ومكانتها في السوق المصرفي.

4.1 اهداف البحث تهدف الدراسة اساسا المى بيان مدى امكانية تبنى العلاقة مع الزبون لدى المصارف قيد الدراسة، فضلا عن تحديد اهداف فرعية اخرى للدراسة موزعة حسب الاتي: - - تحديد اطار نظري للدراسة يستعرض فيه مفهوم ادارة العلاقة مع الزبون. - - تحديد واقع التفكير الذي تتبناه مديري المصارف الاهلية المدروسة تجاه هذا

$$
\text { - } 5.1 \text { فياس ابعاد ادارة العلاقة مع الزبون وفقا لمتطلبات المستفيدين منها. }
$$

يتطلب تننى وتطبيق مفهوم العلاقة مع الزبون ضرورة الاخذ بتقنيات تسويقية جديدة ومفاهيم واستراتيجيات معاصرة تتاقلم مع التغيرات الحاصلة في حاجات ورغبات الزبائن. وبها يككن صياغة فرضية البحث كالأتي (تلعب ادارة المصارف قيد 


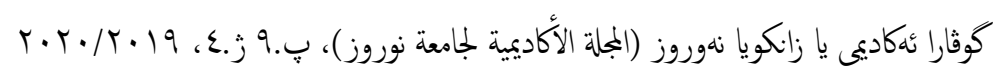

وعرف (نجم ، بانها الاستخدام الواسع لتكنلوجيا (C.R.M) (303: 2005 المعلومات وشبكات الاتصال وبرامجياتها والانظمة الخبيرة من اجل ادامة وتطوير العلاقة مع الزبون. كما تعرف بانها العملية الشاملة لبناء علاقة مربحة مع الزبون والمحافظة عليه من خلال Amstrong \& Kotller ). توصيل قيمه للزبون بشكل رئسي وتحقيق رضاه $(.2005: 23$ أما (Janjicek) فقد عرفها بانها الفلسفة التي تضع الزبون في نقطة تصميم المنتج من اجل توجيه موارد وبجود المنظمة لتقديم افضل المنتجات وتعزيز وتعظيم ولاء الزبون

$$
\text { لها (سليم وهادي، } 2006 \text { : } 4 \text { ). }
$$

و يرى ( الكيكي ، C.R.M ) بأهها إستراتيجية عمل تركز على 2010 : 39 ) بأن الزبائن والتي تهدف إلى زيادة رضا وولاء الزبائن من خلال تقديم منتجات أكثر

$$
\text { استجابة وبحسب الطلب لكل زبون. }
$$

فيا عرفها (عبد الرضا والطائي، 2007 : 234) بانها بموعة بحود شاملة لتحقيق وبناء علاقة متواصلة ومستمرة مع الزبائن وبما يحقق النجاح المشترك لكلا الجانبين. أما (العجمي، 2011 : 16) فيرى بانها إدارة كل تفاعلات الزبون من خلال

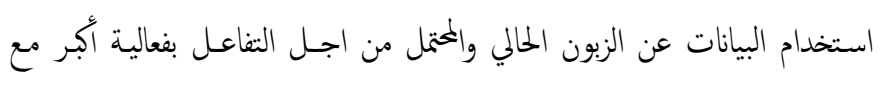
الزبون في كل مراحل العلاقة معه. وتعرفها (بن موسى، 2015 : 4) بأنها تطبيق لمفهوم التسويق بالعلاقة والتي تهدف لإثباع حاجات كل زبون بصفة فردية، من خلال التزكيز على ما يقوله وما تعرفه

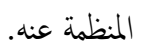
ويرى الباحثان بان مفهوم العلاقة مع الزبون هو تقوية الاواصر بين المصرف وزبائنها 2.2 ومد جسور الثقة معهم في مجال العمل المصرفي.

وهناك من يستخدم مفهومين للزبون هما : (العسكري ،2000 : 116) الزبون المستند على تبادل تجاري محدد

$$
\text { الزبون المستند على تبادل تراكي }
$$

ويشير المفوم الاول إلى المنفعة النهائية التي يجنيها الزبون من المنتج، أما الثاني فيستند إلى ما يسمى إجلالي خبرة شراء أو استخدام المنتج عبر مدة زمنية.
المصدر: من اعداد الباحثان

$$
\text { توزيع فقرات البحث وفقاً لمقايسها }
$$

\section{1}

استعان الباحثان بمجموعة من الادوات الاحصائية لوصف ابعاد متغير البحث

$$
\text { وتشخيصها بواسطة برنامج \}) وSPS V.24) وتثلت هذه الادوات بالاتي: }
$$

(Frequency, Percentage, Mean, Standard Division \& Test

Value)

\section{1}

تم اجراء البحث في القطاع المصرفي بشكل عام ليمثل مجتمعا للبحث الحالي وتم اجراء البحث الحالي في عدد من المصارف الهملية في مدينة دهوك لتكون عينة البحث. وتم اختيار عدد من مديري هذه المصارف ليكون مجالا تطبيقيا للبحث، وبلغت عدد الاستمارات الموزعة على مديري هذه المصارف (40) استمارة واعيد منها (33) استمارة صالحة للتحليل بمعدل استجابة (82.5 \%). 1.2
مفهوم الزمور الثاني: الجانب النظري للبحث - العلاقة مع الزبون وانواعه

كان لبداية الألفية الثالثة تغيرا جوهرياً لمفاهيم التسويق التي كانت سائدة في الماضي, والمفاهيم الجديدة جاءت تلبية للتغيرات الكبيرة والمتسارعة في كافة المجالات والتي أثرت على فلسفة عمل الأنشطة التسويقية في المنظلات بالشكل الذي يواكب تطور حاجات ورغبات الزبائن وبالتالي تحقيق الرضا والولاء للمنظمة الامر الذي أصبح هدفاً استراتيجياً من أهداف المنظمة وادارة تسويقها اذ تمثل إدارة العلاقة مع الزبون الدور المركزي للتسويق المعاصر (الصميدعي ويوسف، 2010 : 192). كما أن تطور مصطلح (C.R.M) جائت نتيجة للتطور الحاصل في حقل التسويق لفترة ليست بالقصيرة وخاصة بعدما تم ادخال النكنولوجيا في الجملات الادارية والتسويقية . ويرى (Zavareh, 2007, 1) أن أصل مفهوم إدارة علاقة الزبون يرجع إلى المفهوم الإداري للتسويق بالعلاقات، وإن سبب ظهوره هو الاختلاف في عادات ومتطلبات وتضضيلات الزبائن، فضلاً عن زيادة المنافسة على السعر وانخفاض ولاء

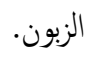




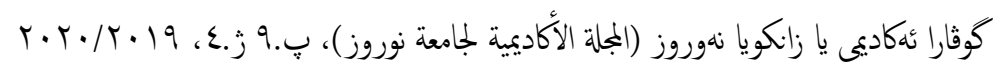

الزبون الإستراتيجي: هو الأكثر مردودية، ويمتاز بمستوى ولاء عال

لمنتجات المنظمة.

الزبون التكثيكي: أقل مردودية الح انه يحتل مكانة مهمة ضمن إنشغالات

$$
\text { المنظمة من خلال سعيها لرفعه إلى مستوى أفضل. }
$$

الزبون الروتيني: هذا النوع من الزبائن يتساوى إحتال إستمراره في

التعامل مع المنظمة مع إحتمال قطعه وإنهاء العلاقة معها، فهو يمثل فرصة

$$
\text { وتهديد للمنظمة في نفس الوقت. }
$$

ويتفق الباحثان مع هذه التصنيفات الخاصة بالزبون والتي من خلالها يستطيع المصرف تقسيم وتصنيف زبائنه الى مربجين وغير مربكين وكيفية التعامل معهم والحفاظ عليه.

\section{2 مفهوم العلاقة بين الزبون والمصرف}

اغلب زبائن المصرف سوف يبقون على ولائم لها اذا كانت قيمة ما يحصلون عليه اعظم نسبيا مما يتوقعون الحصول عليه من المنافسين وبما ان الولاء يعبر عن معاودة الزبائن وتكرارهم التعامل مع المصرف فان ذلك يؤثر على مدى قناعته بما تقدهه المصرف من خدمات حيث يفضل الزبائن دائما المنظمة التي تتسم منتجاتها بجودة ومواصفات وخصائص تتطابق مع حاجاتهم ورغباتهم وبتالي تؤدي الى بناء الولاء

لتلك المنظمة (الخفاجي، 2012 : 88) وعلى الرغز من وجود علاقة أكيدة بين جودة المنتج ورضا الزبون، إلا أن الأكاديمين مازالوا غير متفقين على أرضية عمل مشتركة بخصوص مفهوي جودة المنتج والرضا، إذ أنهم لا يمتلكون رؤية واضحة ودقيقة لتفسير طبيعة الترابط وماهيته. إذ ميز

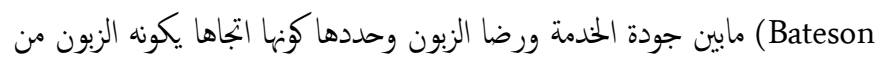
خلال تقيهه لعرض المنتج، وأن هذا الموقف غالبا ما يكون مبنيا أو مستندا على

$$
\text { سلسلة من خبرات تقييمة سابقة ( خثيرو مرابي، } 2017 \text { :34). }
$$
ويرى الباحثان على ان مفهوم العلاقة بين المصرف والزبون يعتمد على درجة شخصينه والعرض والمرونة الممتمدة على الزبون وعلى درجة توافر البيانات والمعلومات. وحيث يتم تقييم فعالية العلاقة بينها على تقييم مدى كفاءة البيانات في تفعيل العلاقة مع الزبون من خلال ادوات عديدة لعل اهها قيمة حياة الزبون وتتيم اسباب فنل العلاقة بين المصرف والزبون وان لتحسين العلاقة بينها يجب ان تتفاعل كل عناصر
أما ( عائشة ، 2011 : 91-92) فقد صنفت الزبون كما يلي :

أ. التصنيف على أساس الخصائص الشخصية: حيث أدرج الباحثان تحت هذا

المعيار عدة أنماط شخصية يمكن أن يتعامل معه:

الزبون الصامت: يتصف بقلة الكلام، ومن الصعب كثف ما يدور في

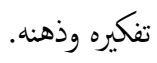

الزبون الثرثار: وهو الزبون الذي يتصف بالتكلم طوال الوقت، يحب

المجادلة والنقاش، إجتماعي، متحمس غير منطقي في الرد، لذا يجتاج إلى

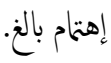

الزبون السلبي: من صفاته الخجل والمزاجية وكثرة الأسئلة، بطيء في

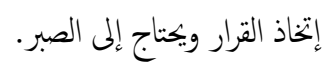

الزبون المتشكك: يمتاز بشكه الدائم وعدم الثقة، من الصعوبة فهمه، هذا النوع يجتاج إلى عدم مجادلنه ومعرفة أسباب شكه وعدم الثقة لديه، ومحاولة بناء جسور الثقة معه من خلال إعطاءه ضانات وأدلة صادقة. الزبون المغرور المندفع: يتصف بالتلقائية، والغضب بسرعة وعدم الصبر ، فهو يعتقد بأنه الأفضل بين الزبائن، لذا يحتاج إلى محاورته والإنتهاء بسرعة من خدمته.

الزبون المتزدد: يشعر بالخوف، التحفظ، وغير قادر على إتخاذ القرار بنفسه لذا يجب إثعاره بأن فرص الإختيار أمامه محدودة، والحلول البديلة قليلة. الزبون الغضبان: يتصف بسرعة الغضب، ويسئ للآخرين، ومن الصعوبة إرضاءه، متهجم يجتاج إلى التحلي بالصبر عند التعامل معه ومحاولة

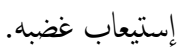
الزبون النوي: يتصف بعدم الإصغاء، ويتخذ قرارات سريعة، هذا النوع يجب مساعدته لتجنب الأخطاء وتقديم النصيحة له، كما يجب إعطاءه المعلومات الضرورية قبل قيامه بإتخاذ القرار.

ب. التصنيف على أساس أهية الزبون بالنسبة للمنظمة: من خلال الأرباح التي يحققها الزبون للمنظمة يمكن تصنيفه إلى: 


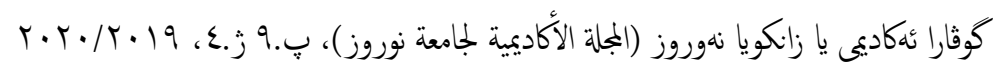

لذا يمكن القول أن العلاقة الناجحة بين المنظمة وزبائها تعمد على إيصال المعلومات للزبون الذي تتوفر فيه رغبة الاتصال وقد ينظر المنظمة حتى يتصل بها بل تسعى لتولد لديه رغبة الاتصال بوسائل معينة وتستعع إليه وتدرك احتياجاته ورغباته وتسعى لنبيتها بتقنيات فعالة ونابحة (عيسى والشيخ ، 2010 : 372 ). 5.2 مكونات العلاقة بين الزبون والمصرف هناك عدد من المكونات الرئيسة للعلاقة بين الزبون والمصرف لعل اههها الاتي: أ. الرضا: يمكن تعريف الرضا من الناحية الشعورية كمملية استجابة إيجابية المنظمة ومن الناحية الإدراكية شعور إيجابي ناتج عن تقييم جوانب العلاقة مع المنظمة ومثثليها وسلوكهم التعاوني ومقارتها بالتوقعات، أي مدى تعويض المنتج بطريقة ملائمة للتضحيات المقدمة لنيله، وإذا جمعنا بين الناحية الإدراكية والشعورية فهو ظاهرة غير ملاحظة أي انه حالة نفية ناتج عن التجربة والمقارنة مع التضضيلات الأساسية (عيسى والشيخ، 2010 : 368-369). ب. الثثة: يعرف الثقة على أنها الإدراك الحسي للثقة في تبادل نزاهة ومصداقية

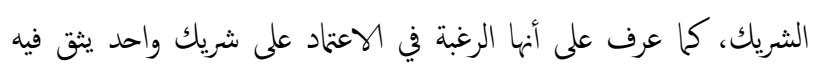
الفرد. فالثقة تعبر عن حالة نفسية لدى الزبون واعتقادات يتولد عنها شعور بالاطمئنان لمصداقية شركاء التبادل باحترامم لوعودهم وأقوالمم (مكتوبة أو مسموعة) ويتزبم هذا الشعور بإرادة في الالتزام من خلال نية في السلوك لتحمل مخاطر العلاقة وهي إما ثقة الزبون في المنتج ذاته أو ثقته في تقيمه الخاص لناك المنتج أو ثقته في مقدم المنتج (المصرف أو من يمثلها). (جلول،

$(90: 2015$

الالتزام المتبادل: يككن القول بان الإلتزام هو عبارة عن سلوك يتبناه الفرد، يعبر عن حالة نفسية وفردية مرتكزة على أحاسيس او معتقدات متعلقة بالمنظمة، عميل تجاري او علامة تجارية، وقد أظهرت المقاربات السلوكية والموقفية

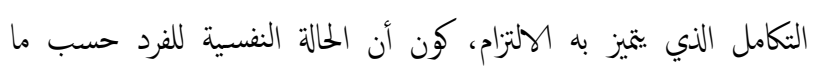
يراها (Allen, Meyer, 1991) يكنها أن تسبق سلوكه أو تلحقه، هن خلال الالتزام تؤثز الاختيارات والسلوكيات السابقة في الاختيارات والسلوكيات اللاحقة. إن تتابع عملية الشراء أو استهلاك نفس العلامة التجارية يعزز في أعين الزبون النكليف المدركة في حالة ما إذاكان هناكك تغيير محتمل للعلامة التجارية (نشوز معرفي، عدم الاستفادة من التكريمات والجوائز،
العلاقة جيدا فضلا عن مستقبل العلاقة مع الزبون اذ ان النظرة المستقبلية لادارة العلاقة مع الزبون تعمد على تحريك العلاقة بين الزبائن ايضا، لذا على المصارف قيد

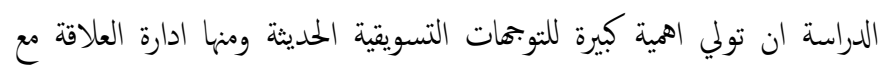
الزبون بالاعتماد على تغعيل العلاقة من خلال تكمل اغلب وسائل الاتصالات الحديثة فضلا عن تفعيل العلاقة بين المصرف والزبون من خلال تلك الادوات من اجل الحفاظ على مكانة المصرف في السوق المصرفي. 4.2 اسباب فشل العلاقة بين المصرف والزبون

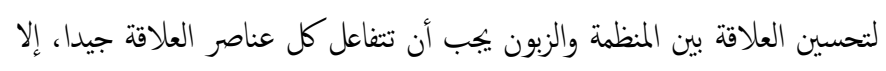
أن هناك أسباب عدة تؤدي المى فشل هذه العلاقة، وهي تظهر في حركية مستمرة كما يلي (ابو فزع، 2015 : 25-26): عندما تصل المعلومات إلى الزبون بشكل جيد ولكن ليس في الوقت المناسب عندما تصل المعلومات إلى الزبون ولكن تنعدم لديه الرغبة في التواصل مع المنظمة. قد تصل المعلومات إلى الزبون ولديه رغبة الاتصال ولكن المنظمة لا يستعع إليه. عندما يستتع المنظمة إلى الزبون ولكنها لا يدرك احتياجاته ورغباته. عندما يدرك المنظمة احتياجات ورغبات الزبون ولكنها لا تستجيب لها. عندما يستجيب المنظمة لاحتياجات الزبون ولكن بوسائل غير فعالة.

تؤدي وسائل الاستجابة غير الفعالة إلى عدم وصول المعلومات للزبون بشكل ج. جيد وهكذا تصبح العلاقة بين المنظمة والزبون تدور في حلقة مفرغة. وهناك عوائق اخرى للعلاقة مع الزبون تظهر الفجوة بين التوقعات والنتائج، فعندما تتوقع المنظمة نمو أدوات التكنولوجيا الخارجية، ولكن تكافؤ الإمكانيات النكنولوجية لدى المنظمة فتصبح هذه الأدوات عوائق، فادارة العلاقة مع الزبون قد تتطلب إرسال بريد إلكتروني للزبائن وضمان وصول نسخة لكل زبون وتفهم العادات الشرائية الفردية وطرق الاتصال المفضلة والذي قد يكون أكبر من إمكانيات المنظمة مثلا مما

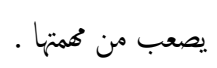




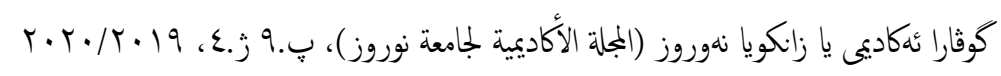

الأهداف المنشودة في المنظمة أو في أي جاعة من الناس ذات نشاط اجتاعي، إذا هي بمثابة خطوط تربط أوصال البناء أو الهيكل التنظيمي لأي منظمة ربطا ديناميكيا، فليس من الممكن أن نتصور جاعة محا كان نشاطها دون أن نتصور في نفس الوقت عملية الاتصال التي تحدث بين فروعها وبين أفرادها وتجعل منها وحدة عضوية لها درجة من النكلمل تسمح بقياهما بنشاطها، وعليه نجد أن الاتصال له الأثر الكبير في نقوس الزبائن،

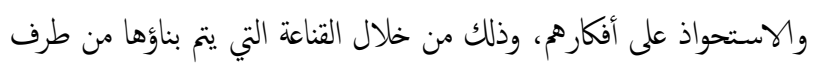
الزبون حتى لا يمكن الثأثير على العلاقة بين الزبون والمنظمة مستقبلاً (العجمي، 2011 : 30). وتعني اعتماد صيغ للتفاعل مع الزبون من خلال التبادل المستمر بين الطرفين في المعلومات لتعزيز سبل المعرفة، وهذا التبادل يتمثل باتجاهين المعلومات التي تحصل عليها المنظمة من الزبون من خلال استطلاع آرائهم لمعرفة مدى رضاهم عن المنتجات المقدمة إليهم حتى يتسنى لها خدمتهم بشكلٍ أفضل والمعلومات التي يحصل عليها الزبون من المنظمة بخصوص منتجاتها التي يهتم بشرائها .وكذلك يشمل الثفاعل مع الزبائن بناء علاقة اجتاعية معهم وليس اعتبارهم مجرد وجوه من دون أسماء، بل هم أصدقاء معروفون بالنسبة لإدارة المنظمة والعاملين فيها. بناء الثقة مع الزبون: ان اي المنظمة تكون هدفها تحقيق ارباح طويلة الامد والنمو والتوسع والحصول على حصة سوقية عالية بالاضافة الى تحقيق ميزة تنافسية يتوجب عليها الاحتفاظ بزبائها. ولان معظم أموال المنظات وأرباحما تحقق من خلال الزبائن الحاليين وليس الزبائن الجدد، وبالتالي فإن خسارة زبون واحد يعني فقدان الكثير من الارباح في المستقبل (البكري ، 11:2014). كما أن المنظمة التي تقوم بالمحافظة على زبائها تكون لها تأثيرا واضحا في زيادة الارباح والنمو، مما يسامي في تعظيم القيمة المالية لها، في حين تكون لها القدرة في تحقيق قيمة الزبون. فالاحتفاظ بالزبون يركز على المعاملة وعادة يجري تبسيطه من خلال جمع معلومات افضل حول متطلبات واحتياجات الزبون, وهنا يتم التزكيز على مستويات اعلى لجودة المنتج وتقديم

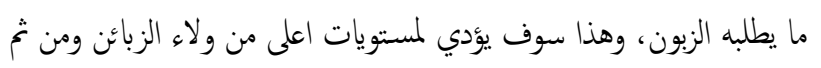

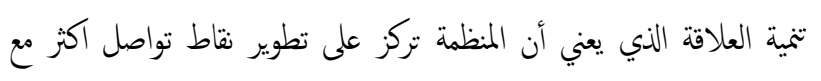
(Robert \& Graham, 2001: زبائها ما يجقق الحفاظ على الزبون
تفضيلات مججوزة للزبائن الأوفياء، تكليف البحث عن المعلومات، بالاضافة الى زيادة مخاطر عدم الرضى)، لذلك يكون للإلتزام دور فعال في تقييم التكليف والمنافع الناجمة عن الحصول على العلامة التجارية (محد، 2010 :

د. الثفاعل: يثير هذا المكون الى أهمية التفاعل بين المنظمة والزبون وذلك من أجل بناء علاقة معه من خلال أدوات الاتصال الحديئة والتكنولوجية المتنوعة، وهذا مـم لان العلاقة يكن فقط أن تعزز بالاستخدام الأمثل لوسائل الاتصال مع الزبون للتعرف على احتياجاته المهمة والمرغوب بها. وتاتي هذه الخطوة لضمان تطوير طرق الاتصال الفعالة مع الزبائن فيه يتعلق بمنتجات المنظمة أو لون لجذب الزبون لحوار مثمر باستخدام التقنيات الحديثة. أذن التفاعل مع الزبون

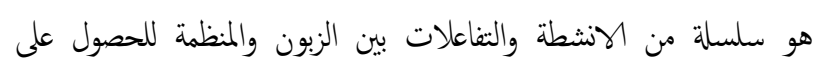
البيانات عن الزبون وتخويلها المى منتجات ومعلومات تشبع حاجاته ورغباته

(حميد، 2015 : 157).

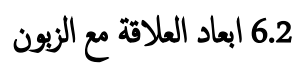

تكمن ابعاد العلاقة مع الزبون في الاتي:

أ. التركيز على الزبون: يعتبر الخطوة الاولى لنجاح ادارة علاقات الزبون ولتحقيق

واستمرار العلاقة معه هي العلاقه مع الزبون عن طريق المنتج التي تقدها المنظمة فضلا عن تعامل المنظمة مع الزبون وكذلك يتحقق الرضا من خلال المنفعة التي يحصل عليها الزبون جراء استخدامه للمنتجات المقدمة. كما يكن القول بان التزكيز على الزبون هو المدى الذي يتطابق به الأداء المدرك للمنتج مع توقعات الزبائن المشترين، فإن اتفق الأداء مع توقعاته، يتحقق رضا الزبون ويكون مبتهجا ومسرورا (Kotler, 2008) (43). وينبني على المنظمة الاهتمام والتزكيز على الأقطاب الثلاثة الوظيفية والتي هي المبيعات والتسويق والخدمات المقدمة للزبائن، إذ يتصل الزبون بالمنظمة سواء قبل البيع أو أثناء البيع أو بعده كجزء من العلاقة المستمرة التي تتطلب تقديم المعلومات الضرورية فضلا عن خيار المشتريات الإضافية الأخرى والتي قد يقدم عليها الزبون (بو

زيد ، 2015 : 20.

ب. الاتصال العالي مع الزبون: يعرف الاتصال على أنه العملية التي يتم من خلالها نقل المعلومات والمعاني والأفكار من شخص إلى آخر أو آخرين بصورة تحقق 


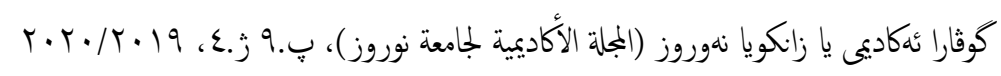

الجدول رةٌ (5) يوضح ان غالبية افراد عينة البحث حاصلين على شهادة البكلوريوس

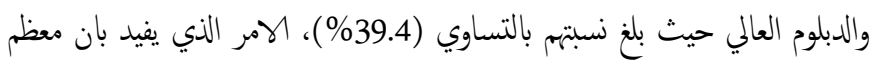

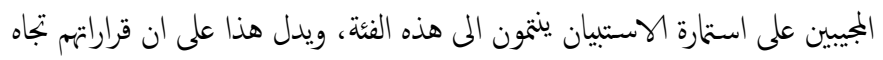

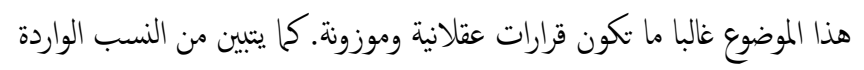

$$
5 \text { الجدول }
$$

وصف أفراد عينة الدراسة حسب الصفات الشخصية

\begin{tabular}{|c|c|c|c|}
\hline النسبة \% & العدد & \multicolumn{2}{|c|}{ توزيع الأفراد المبحوثين حسب } \\
\hline 75.8 & 25 & ذكر & \multirow{2}{*}{ الجنس } \\
\hline 24.2 & 8 & أنثى & \\
\hline 3 & 1 & 25 سنة فا دون & \multirow{4}{*}{ الفئات العمرية } \\
\hline 42.4 & 14 & 26 - 35 سنة & \\
\hline 36.4 & 12 & 36 - 45 سنة & \\
\hline 18.2 & 6 & 46 فاكثر & \\
\hline 9.1 & 3 & شهادة عليا & \multirow{4}{*}{ المؤهل العلمي } \\
\hline 39.4 & 13 & بكالوريوس & \\
\hline 39.4 & 13 & دبلوم معهد & \\
\hline 12.1 & 4 & اعدادية فا دون & \\
\hline 24.2 & 8 & اقل من 5 سنوات & \multirow{3}{*}{ مدة الخدمة في الوظيفة } \\
\hline 51.6 & 17 & 5 - 15 سنة & \\
\hline 24.2 & 8 & 16 فاكثر & \\
\hline 33.3 & 11 & نعم & \multirow{2}{*}{ المشاركة في دورات التدريبية مصرفية } \\
\hline 66.7 & 22 & ע & \\
\hline
\end{tabular}

المصدر: إعداد الباحثان بالاعتماد على تخرجات البرجة الإحصائية (SPSS).

في الجدول (5) ايضا بان الافراد الذين تبلغ مدة خدمتهم في المنظات المبحوثة (5 15 سنة) اذ هم الذين شكلوا النسبة الأعلى في هذه الدراسة وبلغت هذه النسبة (51.6 \% ) من مجموع افراد عينة البحث.كما ييين الجدول (5) ايضا ان (66.7\%) من افراد عينة البحث لم يشاركا في دورات تدريبية مصرفية، في حين ان فقط (33.3 \% \% شاركوا في دورات تدريبية مصرفية. ويتبين المعطيات في الجدول (5) بشكل عام بان الخصائص الشخصية للافراد المبحوثين تدل على امكنية الاجابة على عبارات الاستبانة بشكل جيد نظرا للخصائص الديموغرافية التي يمناكونها.

\section{3 وصف وتشخيص ابعاد العلاقة مع الزبون في المنظلات المبحوثة}

بهدف وصف الابعاد المعتمدة في البحث على مستوى المصارف الاهلية المبحوثة قي مدينة دهوك اعتلادا على التوزيعات التكرارية والاوساط الحسابية والانحرافات المعيارية والتباين لإجابات المبحوثين على أسئلة الاستبانة، وتتناول هذه الفقرة وصف ابعاد العلاقة مع الزبون التي تم الإثارة إلهيا في الجانب النظري للبحث والمتمثلة بالآتي: أ. التركيز على الزبون: تشير النتائُ الواردة في الجدول (6) إلى أن إجابات المبحوثين حول هذا البعد من خلال مؤشراتها (X1-X5) تميل باتجاه الاتفاق
(52) يتوقعه من المنتج وينتج عن رضاه ذاتيا ضرورة وجود عناصر مادية تختص بالأنشطة وذلك لجعل العناصر المعنوية للمنتج ملموسة وذلك بهدف اظهار

$$
\text { الرضا الخفي لدى الزبون (محمد والامين، } 2017 \text { : 162). }
$$

د. التركيز على الاحتفاظ بالزبون: من البدهي القول أن نجاح المنظات بشكل عام يعتمد على قدراتها وامكانياتها في ضهان قاعدة متينة مـن الزبائن الموالين لها، فالمنظمات الناجحة لاتكتفي فقط بأستقطاب الزبائن في المقام

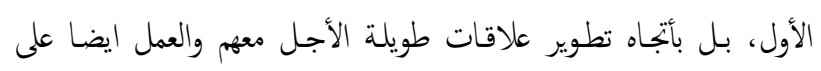
تعزيز هذه العلاقات لتضمن لنفسها البقاء والنمو اذ ان العديد من الزبائن

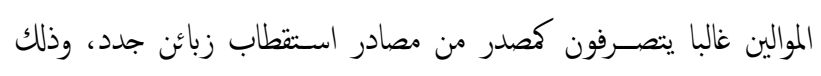
من خلال توصياتهم ومقتراتهم وادائهم الأيجابي والتي يتأثر به الزبائن الجدد (عبيد، 2009 : ويرى كل من (سليم وهادي، 2006: 8) أن الزبائن قد تحولوا الى استثارات مربحة للمنظمة وذلك من خلال عوامل عدة وكما يلي : أ. قدرة المنظمة على فهم سلوك زبنائها وانماطهم الشرائية، وتحويل هذا السلوك المى الامر الواقع بشكل أفضل من بقية المنافسين. ب. حجم الولاء الذي استطاءت المنظمة تكوينه في المراحل السابقة ونجاحما في ادارة العلاقة مع زبائنها. ت. قدرة المنظمة على التجديد والابنكار والابداع من اجل خدمة احتياجات الزبائن المنغيرة. ث. حجم ومستوى المنافسة في السوق وخاصاً في اختيار المنظمة للمزايا التنافسية التي تنفق مع احتياجات زبائها. 3. المحور الثالث: الاطار الميداني يتضمن هذا المحور عدد من الفقرات التي تخص الاطار الميداني للبحث وكالاتي: 1.3 وصف افراد عينة البحث يتبين من خلال الجدول (5) ان (75.8 \%) من افراد عينة البحث من الذكور، في

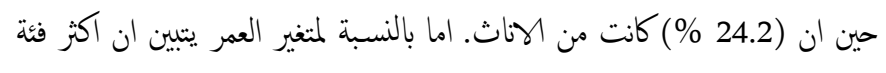

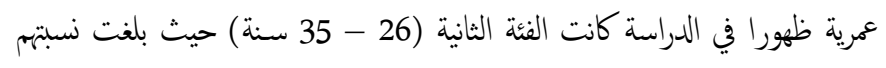

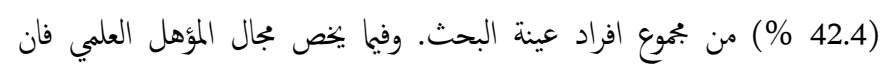




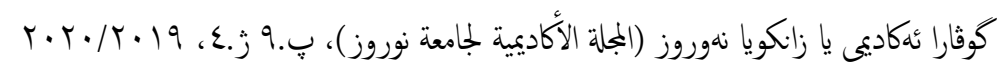

(1.23) والتباين (1.517). وانحصرت قيم الأوساط الحسابية الأخرى للمؤشرات الخاصة بهذا البعد بين الوسط الحسابي للمؤشرين (X6) و(X10). والمعطيات الهحصائية اعلاه تدل بان المصارف قيد الدراسة لدهيا اتصال مع زبائها ولكن ليس بالمستوى المطلوب وهو قليل الى حد ما. بناء الثقة مع الزبون: يتضح من خلال الجدول (6) ان اجابات المبحوثين تجاه هذا البعد من خلال مؤشراتها (X11-X15) تميل باتجاه الاتفاق وبالنسبة (45.48) وذلك بالوسط الحسابي (2.76) وانخراف معياري (1.38) والتباين (1.939) وهذا يدل على الاهتمام الواضح للقيادات الادارية في المصارف

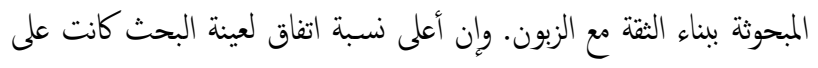
المؤشر (X12) الذي يشير إلى ان موظفوا المصارف المبحوثة يسعى الى بناء علاقات جيدة مع زبائنه. وبلغت نسبة الاتفاق على هذا المؤشر قدره (63.7) ويدعمه وسط حسابي (3.15) وبانراف معياري (1.54) وبالتباين (2.384). ومن اكثر العناصر التي ساهمت في سلبية هذا البعد، قيام المصارف المبحوثة بتحديث وتجديد المعلومات الخاصة بزبائنه والمتمثلة بـ حيث سجلة نسبة الاتفاق فقط (X14) (2.30) وبانحراف معياري (1.51) والتباين (280). وانخصرت قيم الأوساط الحسابية الأخرى للمؤشرات الخاصة بهذا البعد بين الوسط الحسابي

$$
\text { المؤشرين (X16) و) (X11). }
$$

التركيز على الاحتفاظ بالزبون: يتضح من خلال الجدول (6) ان اجابات المبحوثين تجاه هذا البعد من خلال مؤشراتها (X16-X20) تميل باتجاه الاتفاق وبالنسبة (47.28) و حيث بلغ عدم الاتفاق قدره (43.06) بينما بلغ المعدل المحايد (9.7) وذلك بالوسط الحسابي (2.79) وانحراف معياري (1.41) والتباين (2.049) وهذا يدل على الاهتمام الواضح للقيادات الادارية في المصارف المبحوثة بالتزكيز على الزبون. وإن أعلى نسبة اتفاق لعينة البحث كانت على المؤشر (X19) الذي يشير إلى سعى مصارف المبحوثة الى تقديم الخدمة المى زبائنه دون تأخير. وبلغت نسبة الاتفاق على هذا المؤشر قدره (54.6) ويدعمه وسط حسابي (3.06) وبانحراف معياري (1.47) وبالتباين (2.184). ومن اكثر العناصر التي ساهت في سلبية هذا البعد، تيتثل في والتي تنص على انه يسعى المصارف المبحوثة الى الاحتفاظ بالزبائن (X20)
وبنسبة (45.48\%) من تلك الإجابات وبوسط حسابي (2.78) وانحراف معياري (1.44) والتباين (2.101) في حين بلغت سبة عدم الاتفاق على مؤشرات هذا البعد (43.62\%) وهذا يدل على أن هناك اهتماً من قبل عينة البحث بالتركيز على الزبون، وييين الجدول (6) إن أعلى نسبة اتفاق لعينة البحث كانت على المؤشرين X5, X4) الذي يثير إلى ان المصارف المبحوثة تطرح اهم خدماته على الموقع الانتزنيت كما ان مصارف المبحوثة ايضا تستخدم وسائل اتصال متعددة مع زبائنه قياسا بالمنافسين، وبلغت نسبة الاتفاق على مؤشري البعد (48.5\%) من إجابات المبحوثين وبوسط حسابي

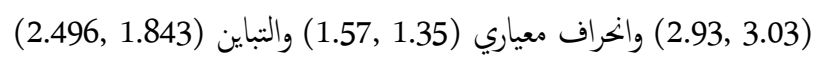
على التوالي. أما أقل نسبة اتفاق فكانت على المؤشر (X3) الذي يشير إلى أن المصارف المبحوثة يمتلك موقع خاص به على الانتزيت، وقد بلغت هذه النسبة (42.4\%) وبلغ الوسط الحسابي لهذا المؤشر (2.87) وبانخراف معياري (1.38) والتباين (1.922). وانحرت قيم الأوساط الحسابية الأخرى للمؤشرات الخاصة بهذا البعد بين الوسط الحسابي للمؤشرين (X5) و(X1). وتدل المعطيات الاحصائية بان المصارف قيد الدراسة تركز على الزبون بشكل مقبول في ادارة العلاقة مع زبائهها. ب. الاتصال العالي مع الزبون: يتضح من معطيات الجدول (6) الخاصة بالاتصال العالي مع الزبون في المصارف المبحوثة، ان هذا البعد تم قياسه بـ (5) اسئلة (x6-x10)، حيث يشير المى وجود معدل الاتفاق لهذا البعد قدره (39.4\%)، في حين بلغ عدم الاتفاق في اجابات المبحوثين (43.66)، بينا بلغ المعدل المحايد فقط (17) من الذين لم تكن لديهم رؤية واضحة عن هذا المتغير، وقد جاء هذا كله بوسط حسابي قدره (2.78) والتباين (1.821) والانحراف المعياري (1.34). وإن أعلى نسبة اتفاق لعينة البحث كانت على المؤشر الذي يشير إلى ان المصارف المبحوثة تقوم بالاتصال بزبائها لتفعيل العلاقة معهم. وبلفت نسبة الاتفاق على هذا المؤشر قدره (51.5) ويدعمه وسط حسابي (3.03) وبانحراف معياري (1.40) والتباين (1.968). ومن اكثر العناصر التي ساهت في عدم ايجابية هذا البعد، هو قيام المصارف المبحوثة بالاتصال مع زبائنه بشكل مستمر والمتمثلة بـ (X6) حيث بلغت نسبة الاتفاق فقط (33.4) ويدعمه وسط حسابي (2.72) وبانراف معياري 


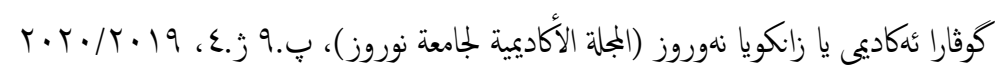

معياري (1.39) والتباين (1.97) وهذا يدل على الاهتمام الواضح للقيادات الادارية في المنظات المبحوثة بالعلاقة مع الزبون. ويوضح الجدول (6) ايضا ان بعد التزكيز على الاحتفاظ بالزبون جاءت بالمرتبة الاولى من حيث القبول وبوسط الحسابي لهذا البعد (2.79) وبانحراف معياري (1.41) والتباين (2.049)، واقل بعد تسجيلا من حيث القبول كان بعد بناء الثقة مع الزبون وذلك بوسط حسابي (2.76) وانخراف معياري (1.38) والتباين (1.939). والنتائج الاحصائية الواردة اعلاه تشير الى صحة اختبار الفرضية الرئيسية للبحث. 4. المحور الرابع: الاستناجات والمقترحات 1.4 الاستنتاجات

من خلال ماتقدم البحث يكن ايجاز اهم الاستنتاجات على الشكل الاتي: اتضح من الجانب النظري أن العلاقة مع الزبون تلعب دورا محا وايجابيا في نجاح المصارف في اعالمم ثم رفع كفاءة المصرف وذلك من خلال خلق نوع من الاستقرار في العلاقات الاجتاعية بين المصرف والزبون.

من خلال الجانب العملي اتضح ان اغلب القيادات الادارية في المصارف المبحوثة سيتمون بالعلاقة مع الزبون وذلك من خلال الاتي: O تبين وجود اتفاق ايجابي منخفض قدره (45.8\%) من قبل افراد عينة البحث حول التركز على الزبون، ويستنجج الباحثان من ذلك بان القيادات الادارية في المصارف المبحوثة يركزون على الزبون ولكن بنسبة قليلة وهذا يساعدهم على التحكم في التعامل مع الزبائنه وبالتالي يدفعهم الى الوصول

\section{لاهدافهم بكفاءة وفاعلية. - مبك.}

O كما تبين وجود اتفاق ضعيف قدره (39.4\%) من قبل افراد عينة البحث حول الاتصال العالي مع الزبون. ويستنج الباحثان من ذلك بان القيادات الادارية في المصارف المبحوثة اهملوا جزئيا التزكيز على الزبون. O أظهرت النتاجُج ايضا وجود اتفاق ايجابي منخفض قدره (45.48\%) من قبل افراد عينة البحث حول بناء الثقة مع الزبون، ويستنتج من ذلك بان

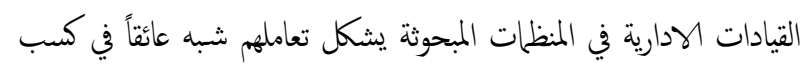

$$
\text { ثقة الزبون. }
$$

القداى فضلا عن كسب زبائن جدد، حيث بلغت نسبة عدمالاتفاق الى (51.6) ويدعمه وسط حسابي (2.60) وبانخراف معياري (1.47) والتباين (2.184). وانحرت قيم الأوساط الحسابية الأخرى للمؤشرات الخاصة بهذا البعد بين الوسط الحسابي للمؤشرين (X20) و(X16). والمعطيات الاحصائية اعلاه تدل بان المصارف قيد الدراسة تركز بشكل قليل في الاحتفاظ بالزبون ضمن ادارة العلاقة مع زبائها الجدول 6 التوزيعات النكرارية والاوساط الحسابية والانخرافات المعيارية والتباين لابعاد العلاقة مع الزبون على مستوى المنظات المبحوثة.

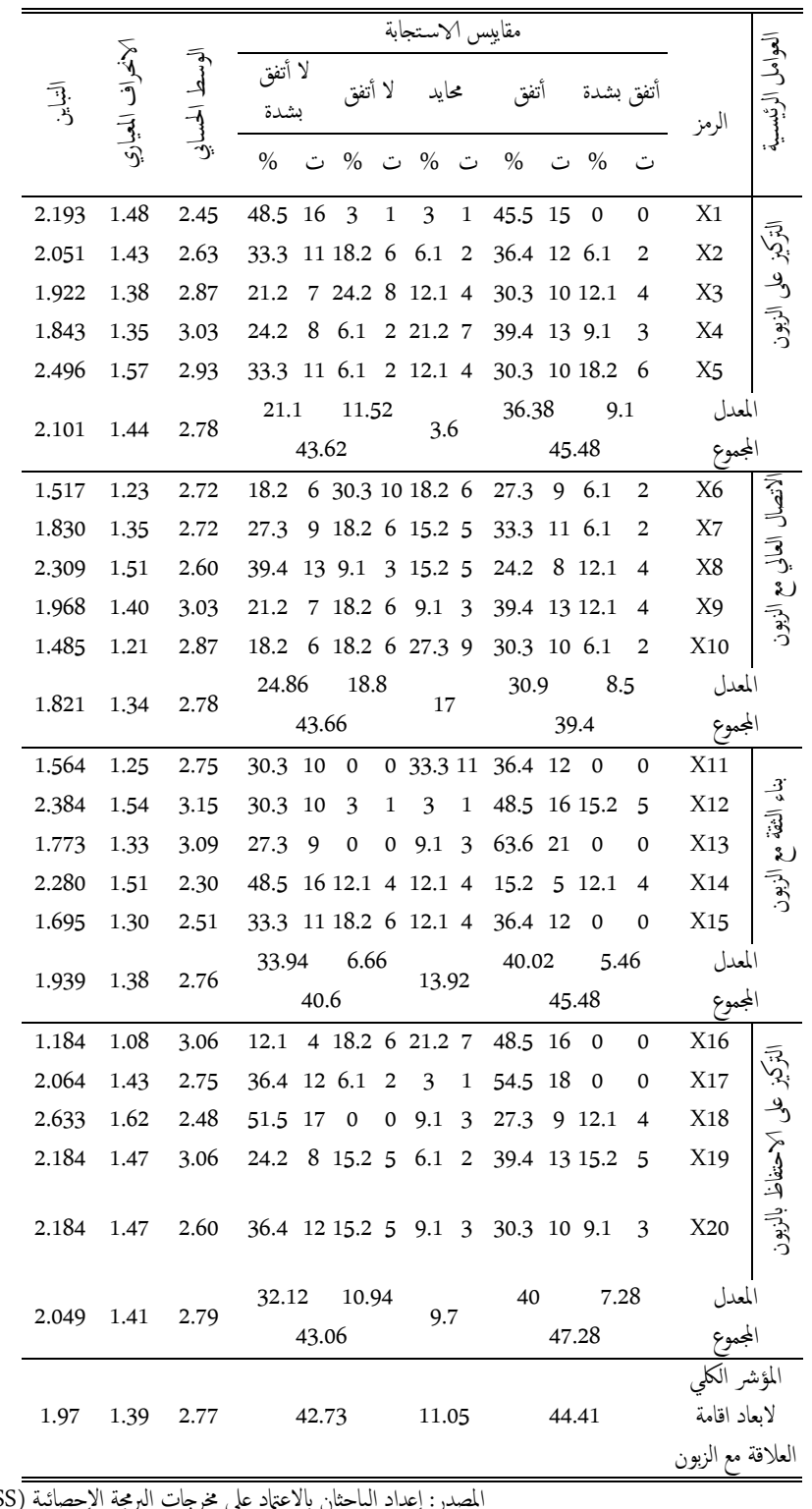
المصدر: إعداد الباحثان بالاعناد على خرجات البرجة الإحصائية (SPSS).

يتضح من خلال الجدول (6) ان اجابات المبحوثين حول ابعاد اقامة العلاقة مع الزبون بشكل عام تميل باتجاه الاتفاق وذلك بالوسط الحسابي (2.77) وانحراف 


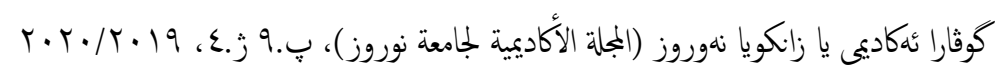

O أظهرت النتائج ايضا وجود اتفاق ايجابي منخفض قدره (44.28\%) من قبل 6.

افراد عينة البحث حول التزكيز على الاحتفاظ بالزبون، ويستنتج من ذلك 1.6 المصادر باللغة العربية

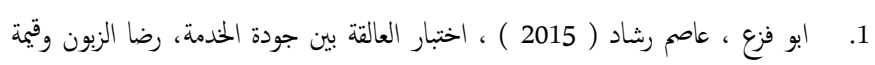

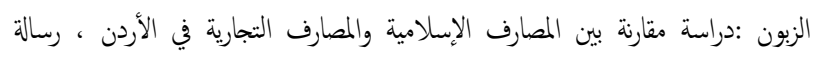

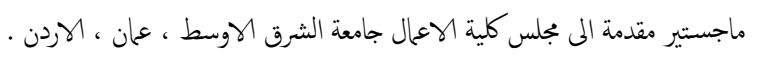

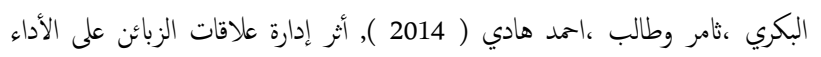

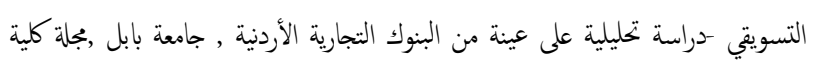

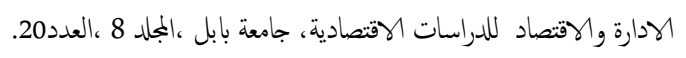

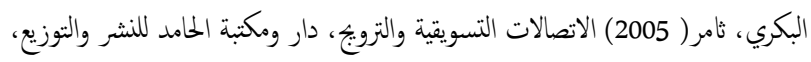
عمان، الاردن.

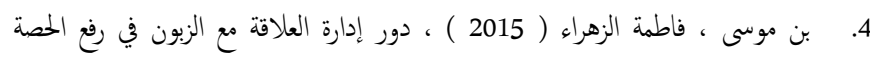

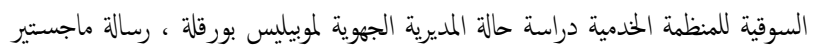

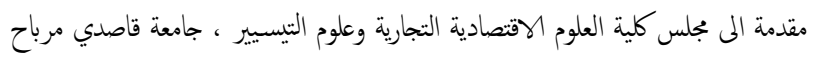
، الجزائر .

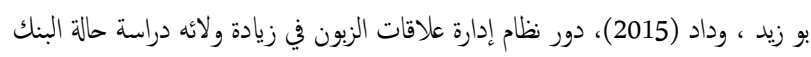

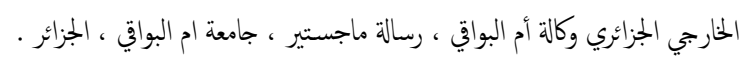

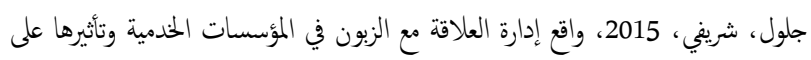

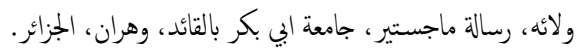

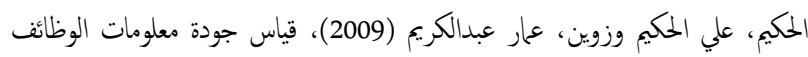

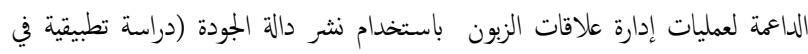
شركة آسيا سيل للاتصالات / فرع النجف)، مجلة القادسية للعلوم الادارية والاقتصادية، البجلد 11 والعدد 3. حميد ، لمى ماجد ( 2015 ) ادارة علاقات الزبون ولاثيرها في تحتيق النجاح الاستراتيجي

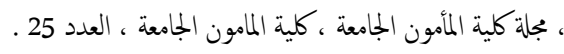

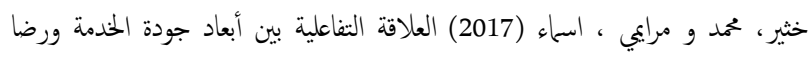
الزبون بالمنظمة ، مجلة الريادة لاقتصاديات الأعال ، بجلد 3 ، ،لعدد 4 ـ.

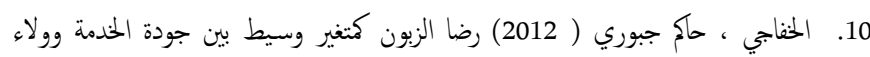

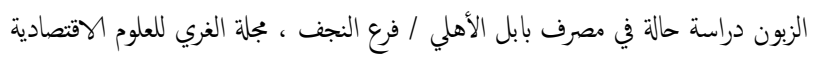
والادارية ، جامعة الكوفة ، مجلد 8 ، العدد 25 .

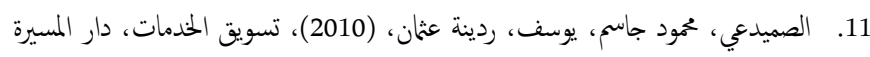
اللنشر والتوزيع، عهان، اردن. 12. الطائي ،يوسف جيم سلطان بان والعبادي هاشم فوزي دباس (2009 ) ادارة علاقات الزبون الوراق للنشر والتوزيع،عان ، الاردن.

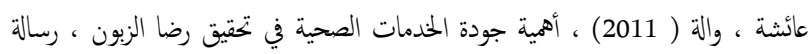
ماجستير ، جامعة الجزائر ، الجزائر.

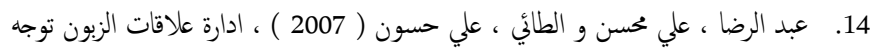

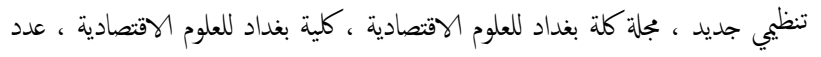

1. عبيد ، معمر عقيل ( 2009 ) ، العلاقة بين رضا الزبون و الإستراتيجيات التسويقية

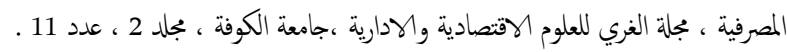
3
بان القيادات الادارية في المصارف المبحوثة هبتمون قليلا بالاحتفاظ الزبون. يستنجج الباحثان من النتائُ اعلاه ان العلاقة مع الزبون يعد مفتاح لحفاظ على الزبون في المنظلات. ولكن المصارف قيد الدراسة اظهرت بان هناك اهتمام بالعلاقة مع الزبون 2. ولكن بنسبة ضعيفة.

2.4

بناءا على نتائُ الدراسة يكن تقديم المقترحات التالية: يوصي الباحثان ادارة المصارف المبحوثة بدراسة العوامل التي تساهم في رفع مستوى العلاقة مع الزبون والعمل على تعزيزها. لان مفهوم العلاقة مع الزبون

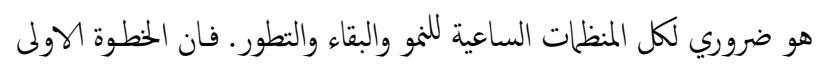
تبدأ من خلال فهم حاجات ورغبات ومفضلات الزبون في الشراء مـ قبل ادارة المصرف وبالتالي اقامة علاقة طوياة الاجل مع الزبائن وكل ذلك يتحقق من خلال استخدام الفلسفة التسويقية الجديدة للعلاقة مع الزبون. توصي الباحثـان ادارة المصـارف المبحوثة بالعمل على رفع قدرة القيـادات الادارية على تحمل الضغوط النفسية والاجتاعية اثنـاء العمل مـن خلال ادخالم في دورات تخصصية لزيادة مستواهم المعرفي والمهاراتي لادارة العلاقة مع الزبون. لان في ظل البيئة التنافسية، فأن المنظلات القادرة على الهسيتمرار هي تلك التي تستطع فهم حاجات ورغبات الزبائن والاستجابة لها بشكل اسرع من الاخرين. ضرورة زيادة فرص التواصل والثفاعل الاجتاعي بين القيـادات الادارية والزبائن والعمل على بث روح المبادرة في تقديم المساعدة والمساندة للعملاء والعمل على حل مشاكلهم. ضرورة تشجيع القيادات الادارية على التعامل مع الزبون وفسح الجمال لهم لتطوير قابلياتهم وتوسيع ادراكهم وديم قدراتهم الابنكرية لكي يكونوا قادرين على اتخاذ القرار المناسب لحل المشاكل التي يمكن ان تواجه المصرف. 


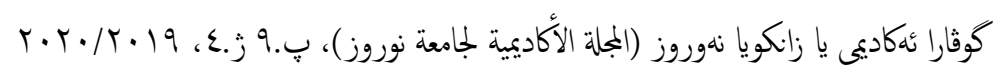

$$
\begin{aligned}
& \text { 16. العجمي ، خلالد شطي مغطي عواد ( 2011) فاعلية ادارة علاقات الزبائن في تحتيق الولاء : }
\end{aligned}
$$

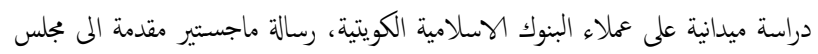

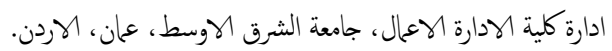

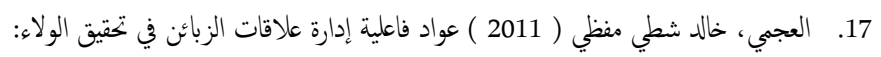

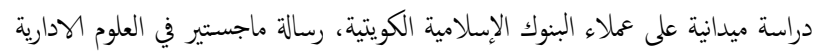

$$
\begin{aligned}
& \text { جامعة الشرق الووسط ، الاردن. }
\end{aligned}
$$

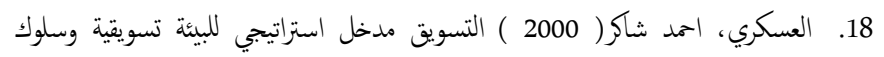

$$
\begin{aligned}
& \text { المستهلكين والمزيخ التسويتي، دار الشروق للنشر والتوزيع، عان، الاردن. }
\end{aligned}
$$

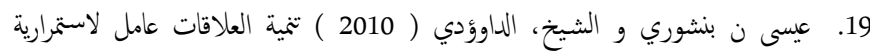

$$
\begin{aligned}
& \text { المؤسسات، مجلة الباحث ، العدد } 7 \text {. }
\end{aligned}
$$

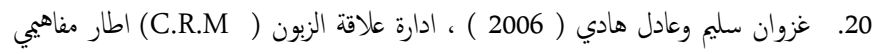

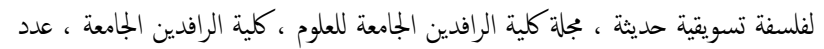

1. Armstrong ,G.,\& Kotler, Ph .,(2005),"Marketing an introduction, 7th ed, pearson, prentice - Hill.

2. Janjicek ,Rose ( 2004 ) " CRM architecture for enterprise relationship management in the millennium " a technical white paper by CHP,www.looksmark.com

3. Johnston Robert \& Clark, Graham,2001, Service Operations Management, Prentice Hall, England.

4. Kotler , Philip,2008 ,Marketing An Introduction ,Pearson Education, New Jerse,USA.

5. Zavareh, Javad Toufighi, 2007, The Role of Analytical CRM in Maximizing Customer Profitability in Private Banking Tow Swedish Banks, http://www.diva-portal.org/smash/record.jsf?pid 


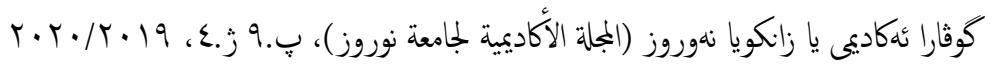

1 الملاحق 1

الملحق 1: اسماء سادة المككين

\begin{tabular}{|c|c|c|}
\hline اللقب العلمي & السادة المكمين & ت \\
\hline استاذ & د. درمان سليان صادق & 1 \\
\hline استاذ مساءد & د. حكمت رشيد سلطان & 2 \\
\hline استاذ مساءد & د. سعد فاضل عباس & 3 \\
\hline استاذ مساعد & د. رفعت محمد علي طه & 4 \\
\hline
\end{tabular}

المصدر: من اعداد الباحثان 


\section{الملحق (2) استمارة الاستبانة}

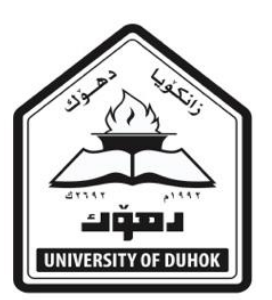

زانكويا دهوك

كوليزًا كاركيزرى وئابوورى

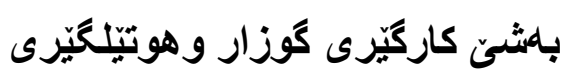

م/ استارة الكستبانة

تمثل هذه الاستمارة جزءا من متطلبات اعداد البحث الموسوم " تبني العلاقة مع الزبون في المنظات الماتية المدمية/ دراسة استطلاعية لآراء عينة

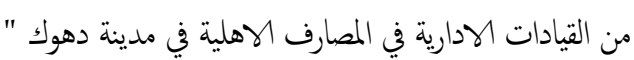

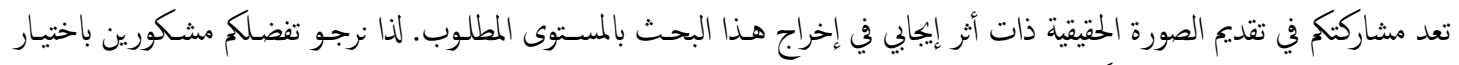

الإجابة التي ترونها مناسبة لكل سؤال، علماً بأن البيانات المدونة تنسم بطابع ألمابع السرية والأمانة العلمية.

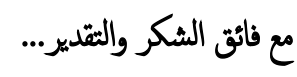

الباحث

أولاً. المعلومات الشخصية

-1 الجنس: ذكر $\square$ أنى

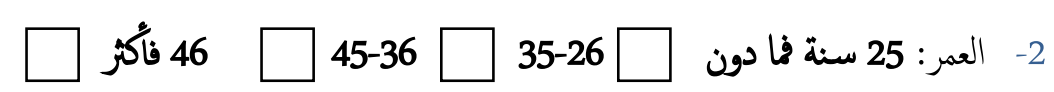

3- المؤهل العلمي: شهادة عليا $\square$

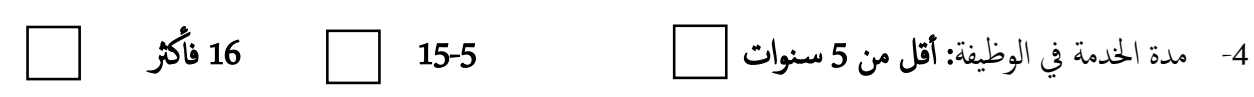

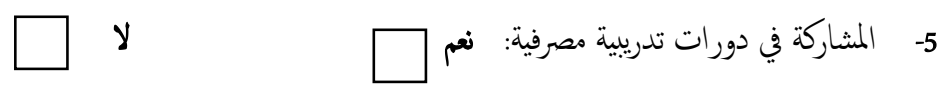


1 انانياً. الأسئلة المتعلةة بمثغيرات الدراسة

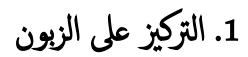

\begin{tabular}{|c|c|c|c|c|c|c|}
\hline لا اتفق & لا لا تقق & معايد & اثفق & اتفق بشدة & الققرات & $ت$ \\
\hline & & & & & يقوم مصرفك بالتعرف على اهم زبائنه المربين & 1 \\
\hline & & & & & يعلم مصرفكم زبائنه بالخدمات المصرفية الجديدة & 2 \\
\hline & & & & & يميناك مصرفكم موقع خاص به على الانتريت & 3 \\
\hline & & & & & يطرح مصرفكم اهم خدماته على موقع الانتزنيت & 4 \\
\hline & & & & & يزود مصرفكم زبائنه بالمعلومات الكاملة عن الطلب الملائم & 5 \\
\hline
\end{tabular}

2: - 2 الاتصال العالي مع الزبون

\begin{tabular}{|c|c|c|c|c|c|c|}
\hline لا الثدة & لا اتفق & محايد & 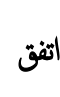 & 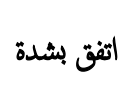 & 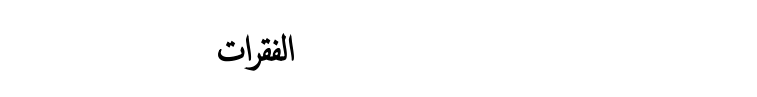 & $ت$ \\
\hline & & & & & يقوم مصرفك بالاتصال مع زبائنه بشكل مستمر & 1 \\
\hline & & & & & يستخدم مصرفكم وسائل اتصال حديثة مع زبائنه & 2 \\
\hline & & & & & يقدم مصرفكى خدمات استشارية لزبائنه بعد بيع الخدمة المصرفية & 3 \\
\hline & & & & & يقوم مصرفكم بالاتصال بزبائنه لتفعيل العلاقة معهم & 4 \\
\hline & & & & & يتميز مصرفكم باستخدام وسائل اتصال متعددة مع زبائنه قياسا بالمنافسين & 5 \\
\hline
\end{tabular}

3: - بناء الثقة مع الزبون

\begin{tabular}{|c|c|c|c|c|c|c|}
\hline لا لا اتفق & 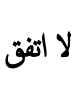 & معايد & 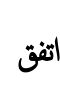 & اتفق بشدة & 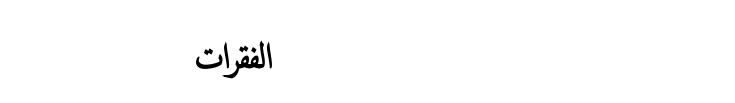 & ت \\
\hline & & & & & يستخدم مصرفكم سياسة مشاركة الزبون مع المصرف لبناء العلاقة معه & 1 \\
\hline & & & & & يسعى موظفوا مصرفك الى بناء علاقات جيدة مع زبائنه & 2 \\
\hline & & & & & يقدم مصرفكم معلومات بصورة واضحة الى زبائنه لكسب ثقته & 3 \\
\hline & & & & & يقوم مصرفكم بتحديث وتجديد المعلومات الخاصة بزبائنه & 4 \\
\hline & & & & & يمتلك مصرفكم قاعدة بيانات عن كل زبائنه & 5 \\
\hline
\end{tabular}

4: التركيز على الاحتفاظ بالزبون

\begin{tabular}{|c|c|c|c|c|c|c|}
\hline لا اتفق & 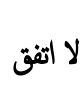 & معايد & اتفق - اتق & 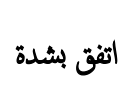 & 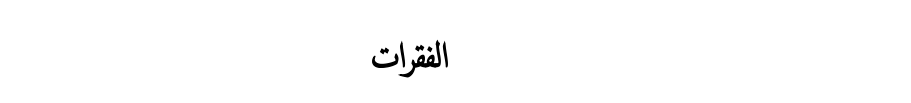 & $ت$ \\
\hline & & & & & يبني مصرفكى برنامج تسويقي للتعامل مع شكاوى الزبائن والتقليل من معدلات التسرب & 1 \\
\hline & & & & & يضع مصرفك المصلحة العليا للزبون في اولى اهتماته & 2 \\
\hline & & & & & تساعد قاعدة بيانات الزبون في مصرفكم على كيفة الاحتفاظ بشريحة معينة من الزبائن & 3 \\
\hline & & & & & يسعى مصرفك الى تقديم الخدمة الى زبائنه دون تأخير & 4 \\
\hline & & & & & يسعى مصرفك الى الاحتفاظ بالزبائن القدام فضلا عن كسب زبائن جدد & 5 \\
\hline
\end{tabular}

